\title{
DIAGNOSTICS OF THE TRACK SUBSTRUCTURE MODEL AND ITS PRACTICAL USE
}

The paper presents mathematical equations of dependence of deformation resistance (compaction degree) and static/dynamic deformation module of elasticity reached by experimental measurements at laboratory model of scale 1:1 in 2003 and 2004. Recommendations for practice from the point of view of dimensioning and suitability of applied materials into the railway substructure are also presented.

\section{Introduction}

Intensity of traffic loading of a railway construction is a basic factor which influences its composition and arrangement to fulfil the expected function during its durability. Loading of railway lines, especially corridor localities, is supposed to grow because of denser traffic caused not only by the increase of axles loadings, but also by higher traffic speeds. Hence, the high quality of the railway line, especially the railway substructure, has to meet these requirements. Even small defects in geometrical rail position caused by permanent deformations of the railway substructure or the whole ground body subsidence can bring the growth of dynamic strengths having the impulse effect which exceeds the static loading. This fact can lead not only to decrease of traffic safety, but also to the further degradation of the railway substructure. Therefore the choice of suitable ground material and elements of the railway substructure and their proper building-in leads to decreasing of its permanent deformations. This seems to be more efficient than traffic with less axle tension and lower speed in the past.

Dimensioning of the construction thickness of particular layers of the ground material, and also the right choice and building-in of the construction elements (geosynthetics) appears to be important when designing the railway substructure. According to [1], the equivalent static module of deformation of the examined construction is the determining parameter for the design. It is realized by a static loading test at Slovak Railways (SR). The theory of elastic half-space by Ivanov, known as Dornii method is used for calculating substructure layers thickness. Limited conditions of this theoretical solution do not allow to take into consideration a number of factors influencing the construction deformation resistance (bearing capacity), e.g. the type of ground material from the point of view of its granularity, the condition of built-in material from the point of view of its compaction and synergism of individual construction elements (e. g. geosynthetics) with ground surrounding. The monitoring of a real construction or similar model appears to be a reliable way of considering such limitations in designing and dimensioning the railway substructure. The experimental model measurements make it possible to simulate the railway substructure into real conditions. Such a construction will take into consideration a number of real limited conditions and will guarantee economical and reliable construction design.

The Department of Railway Engineering and Track Management (DRETM) of the University of Žilina built a railway substructure model in the scale 1:1 for experimental testing of various ground materials and construction elements under specific conditions. The dependence of static loading tests results and dynamic loading tests results regarding dynamic influence on substructure material and other elements in the railway substructure is shown. Advancing diagnostics of the deformation resistance (bearing capacity) of the construction is monitored on this model.

\section{Description of the railway substructure model}

The model of the railway substructure construction at DRETM is built in a steel testing stand with the ground-plan dimensions of $3400 \mathrm{~mm} \times 1950 \mathrm{~mm}$ and the height of $1200 \mathrm{~mm}$ (Fig. 1). The testing stand walls are reinforced by vertical steel profiles (reinforced ribs) to reach transversal and longitudinal stability. There is a transversal steel beam in the upper part of the stand which is fastened on two side poles with possibility to fix them in three exactly specified positions lengthwise the stand. This transversal beam serves as a counter balance for static loading tests. The configuration of the testing stand (Fig. 1) and static loading test conditions make it possible to test in six places (positions $A 1-C 2$ ) in such a way that the realized tests are not influenced by stiffness of the walls.

Material used for the model of the railway substructure is sandy clay which forms the subgrade surface with thickness of $600 \mathrm{~mm}$ and granulated gravel with fraction of $0 / 32 \mathrm{~mm}$ which was applied into the subbase (with thickness of 150, 300, 450 and $600 \mathrm{~mm}$ ). Granulated gravel has various granulometric curves corresponding to the granularity given in the Slovak Technical Standard (STN) 721512 (at present replaced by STN EN 13242) (Fig. 2).

\footnotetext{
* Libor Ižvolt, Ján Kardoš, Ján Lelak, Martin Mečár

Department of Railway Engineering and Track Management, Faculty of Civil Engineering, University of Žilina, Komenského 52, SK-010 26 Žilina, Slovakia, E-mail: libori@fstav.utc.sk, kardos@fstav.utc.sk, jose@fstav.utc.sk, mecar@fstav.utc.sk
} 

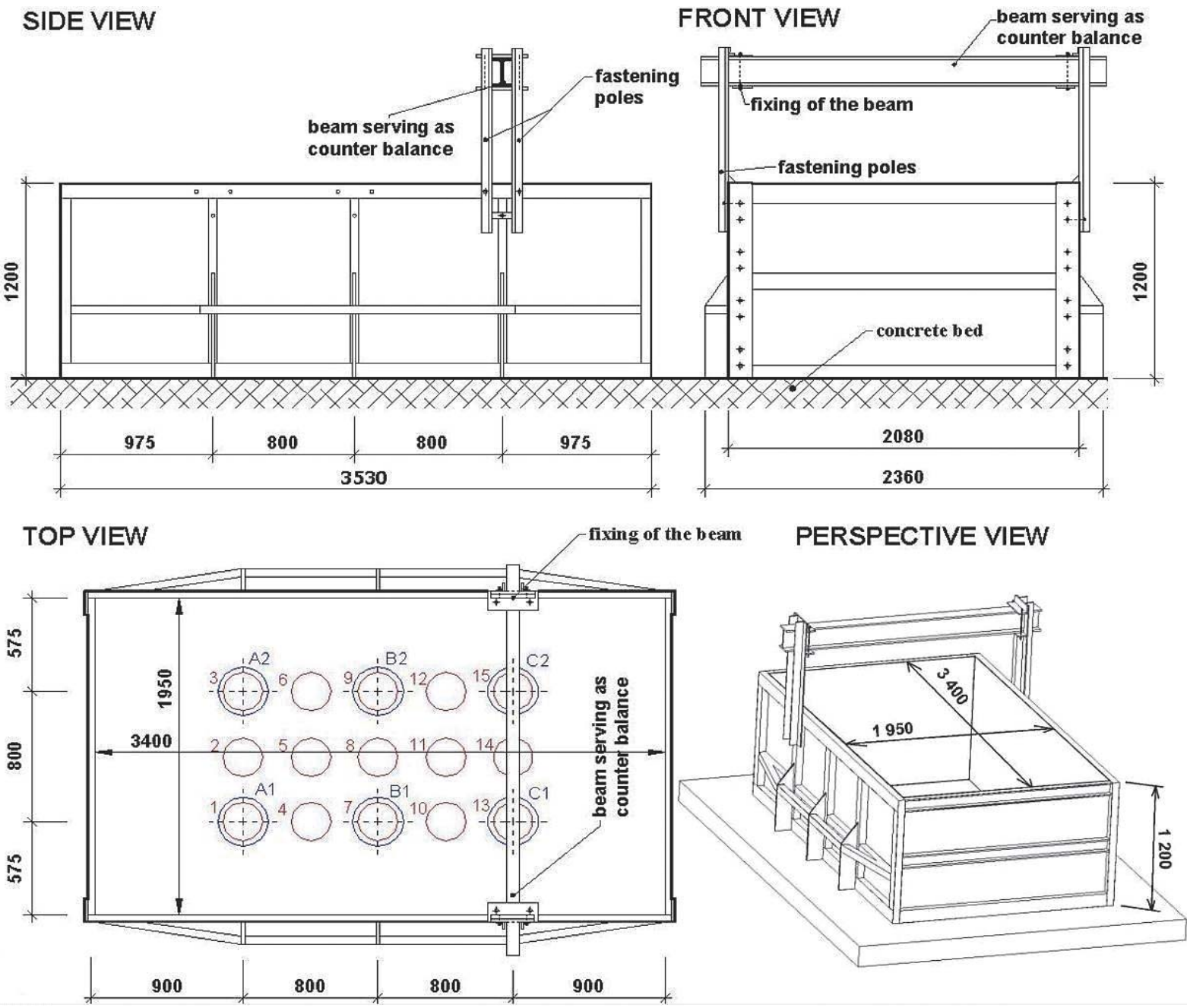

Fig. 1. View of the testing stand

Geosynthetics has a filtering reinforced function and was applied between the subgrade surface and the subbase during each experimental measurement

\section{Methodology of experimental measurements}

Deformation characteristics of the examined railway substructure models were determined by static and dynamic loading tests according to the mended annex No.20 of the regulation S4 "Railway Substructure" [1]. The principle of determining the deformation resistance of the construction is based on creating the real loading (static, impulse) on the tested construction in order to induce certain deformation (plastic, elastic). Measurement of this deformation depends not only on the type of ground, but also on compaction of loose material and its loading (static, dynamic).

The static plate loading test (SPLT) was realized in two cycles with the maximum pressure of $0.20 \mathrm{MPa}$ under a circular plate. Time sequence of loading levels is shown in Fig. 3. The particular loading level was maintained until the deformation of the subgrade changed in the value lower than $0.02 \mathrm{~mm}$ per minute $\left(T_{i}\right)$. The static deformation module $E_{s(0, e k v)}$ is calculated from the measured data according to the equation:

$$
E_{s}=\frac{1.5 \cdot p \cdot r}{y}(\mathrm{MPa})
$$

Where:

$p \quad$ is the specific pressure under the loading plate $(0.10 \mathrm{MPa}$, or $0.20 \mathrm{MPa}$ ),

$r$ is the radius of the loading plate $(0.15 \mathrm{~m})$,

$y$ is the total compaction of the loading plate in meters,

1.5 is the constant taking into consideration the plate shape and Poisson 's ratio of tested material.

The compaction degree of construction layer was determined from deformation decreases of the plate measured in two loading cycles according to the equation: 


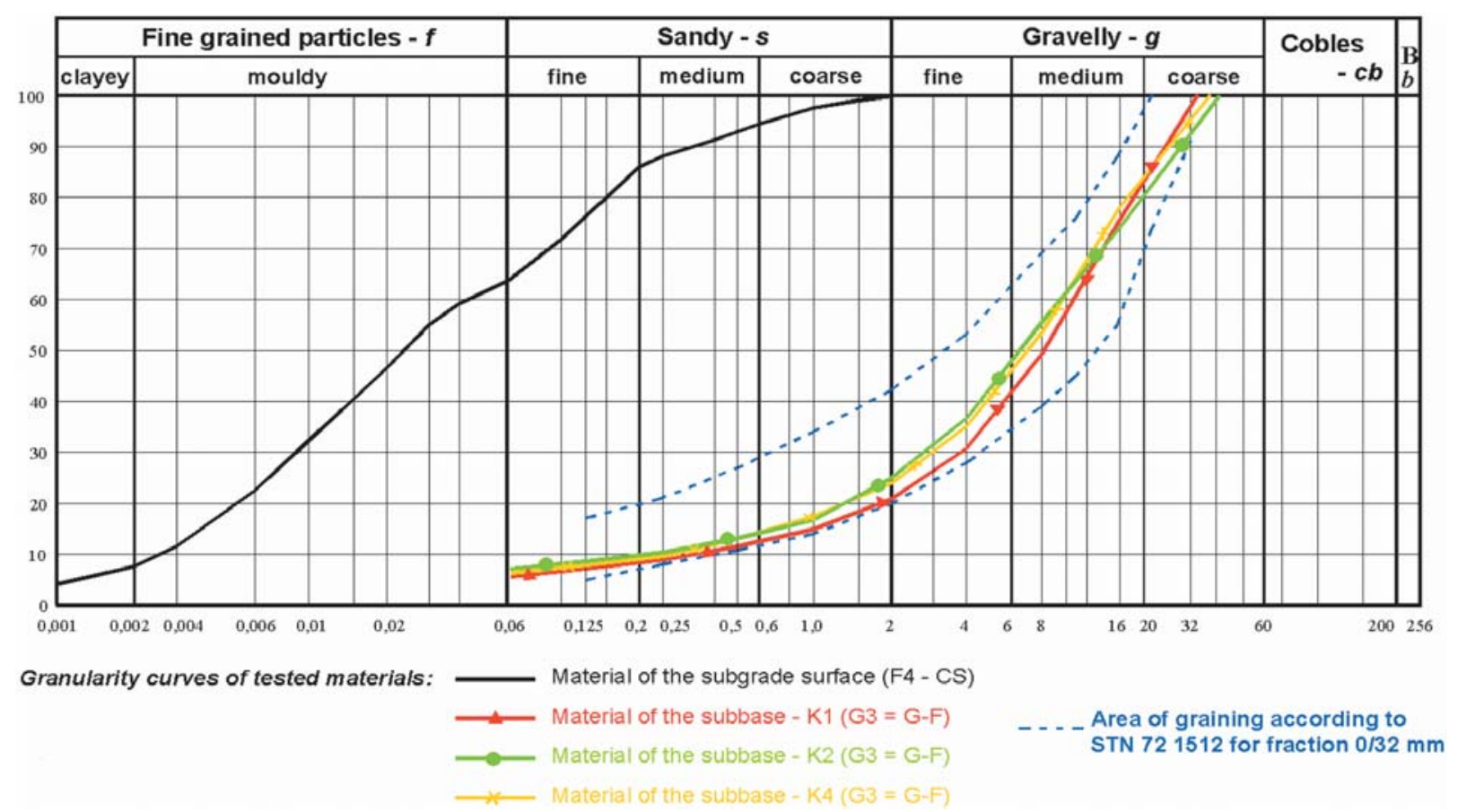

Fig. 2. Granularity curves of materials applied to the model of the railway substructure
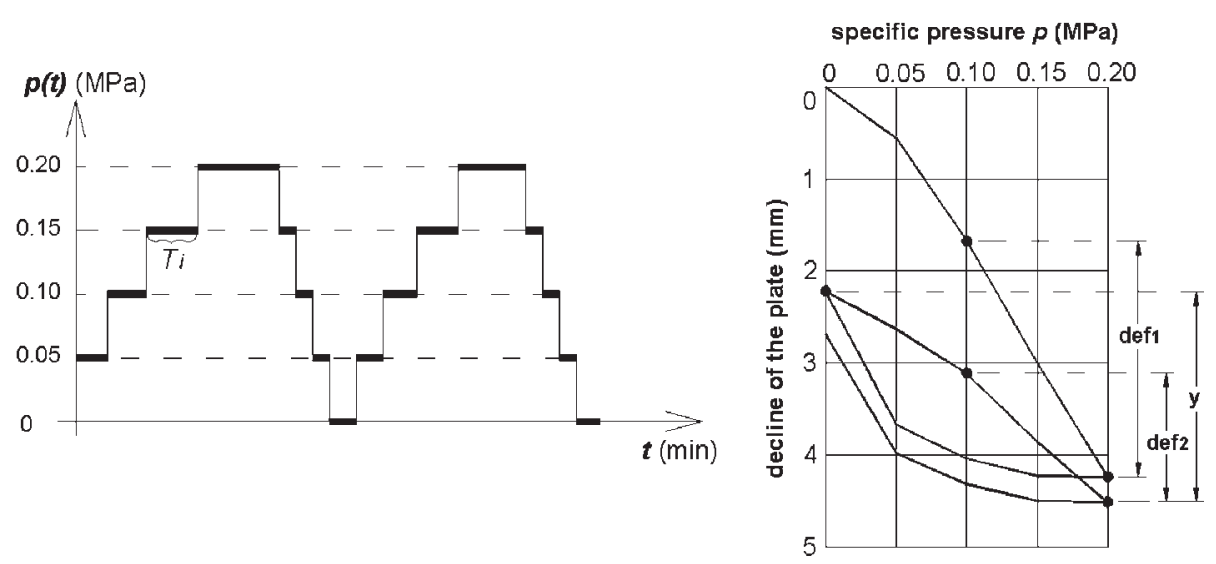

Fig. 3. Work diagrams of SPLT

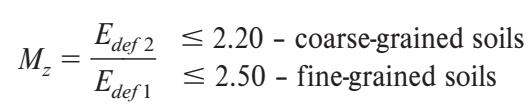

Quality of compaction $M_{z}$ of the construction layer of the railway substructure is suitable if the above mentioned conditions are fulfilled.

The dynamic plate loading test (DPLT) was realized by a light impulse instrument with a circular plate with the diameter of $0.30 \mathrm{~m}$. Impulse loading in the form of a sinusoid was generated by falling ballast on the impulse absorber and caused maximum contact tension of $0.10 \mathrm{MPa}$ with the impulse length of $18 \mathrm{~ms}$ under the plate. The graph of impulse tension function under the plate and the output of dynamic test is shown in Fig. 4.

The dynamic module of elasticity $E_{d(e k v)}$ was calculated from the measured data according to the following relation:

$$
E_{d}=\frac{1.5 \cdot r \cdot \sigma}{y_{e l}}(\mathrm{MPa})
$$

Where:

$r \quad$ is the radius of the loading plate $(0.15 \mathrm{~m})$,

$\sigma$ is the maximum loading pressure under the loading plate (0.10 MPa), 

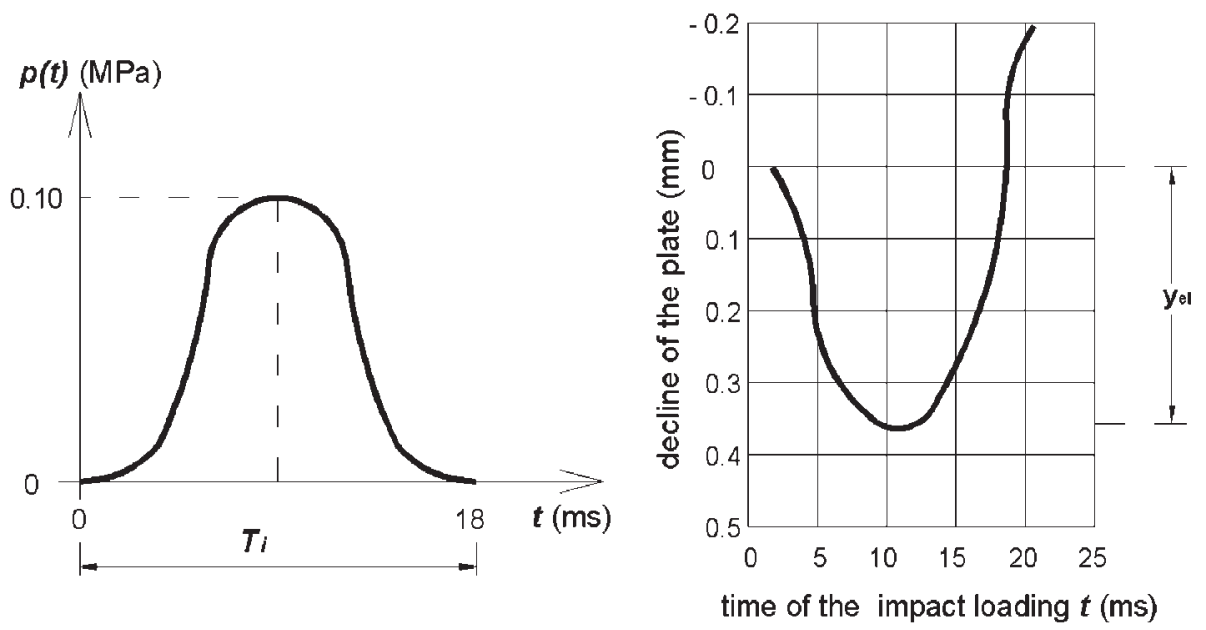

Fig. 4. Work diagrams of DPLT

$y_{e l}$ is the size of elastic movement under the plate,

1.5 is the constant taking into consideration the plate shape and Poisson`s ratio of tested material.

\section{Regression and correlation analysis of dependence $\mathrm{E}_{\mathrm{ekv}} / \mathrm{M}_{\mathrm{z}}$}

Construction elements applied into ground, as well as granulometric composition of ground and the ground compaction degree remarkably influence the deformation resistance of the railway substructure construction. It is inevitable to determine the dependence between the equivalent deformation module $E_{e k v}$ and the compaction degree $M_{z}$ on various railway substructures to use these prospectively. After determining regression equations it is possible to examine the railway substructure construction also from the economic point of view, i.e. if it is more advantageous to increase compaction or volume of used material, or to apply a geosynthetic element for reinforcing a structure.

In the following text there are three various compositions of the monitored railway substructure models described:

\section{Construction No. 1 Construction No. 2 Construction No. 3 \\ - subgrade surface - subgrade surface - subgrade surface \\ - separating geotex- - reinforcing geo- - separating geotex- tile composite tile \\ - subbase with thick- - subbase with thick- - non-rigid geogrid ness of $150-600$ ness of $150-600$ - subbase with thick- $\mathrm{mm} \quad \mathrm{mm}$ ness of $150-600$ $\mathrm{mm}$}

To achieve the same deformation resistance of the subgrade surface on all tested constructions was the basic assumption for determining relevant dependence $E_{e k v} / M_{z}$. This requirement was fulfilled and the subgrade surface deformation resistance about
$E_{0}=7.0 \mathrm{MPa}$ was achieved in all tested railway substructure constructions. Subbase material was another constant factor. It consisted of gravel crushed material with fraction of $0 / 32 \mathrm{~mm}-$ fractional crushed gravel $K 1$ (Fig. 2)

Geosynthetics was applied on the subgrade surface in the testing stand and was fixed along the perimeter with steel mandrels. Then the subbase material was being added to the calculated height in order to achieve the required thickness and compaction degree of the layer after (compaction with the compacting equipment ViDo 25/40). The subbase was gradually built from the thickness of $150 \mathrm{~mm}$ up to the thickness of $600 \mathrm{~mm}$; the thickness of each step was $150 \mathrm{~mm}$ in order to follow deformation resistance of the construction in dependence on the subbase thickness. Six SPLT were realized on each particular layer of the railway substructure, i.e. 36 experimental tests for one cycle; (on the subgrade surface before and after cycle; on the subbase layer with the thickness of $150 \mathrm{~mm}, 300 \mathrm{~mm}, 450 \mathrm{~mm}, 600 \mathrm{~mm}$ ). 108 results of static loading tests were analysed in total.

Tab. 1 presents a survey of total equivalent module of deformation $E_{e k v}$ and compaction degree $M_{z}$ in dependence on the type of tested construction and position of measurement on the construction layer. The average values of the equivalent module of deformation $E_{e k v}$ for one construction layer were determined by means of the simple averaging of six reached results on one layer in positions $A 1$ - $C 2$ (Fig. 1). Average values of the degree of compaction $M_{z}$ presented in Tab. 1 were determined statistically from all the measured dependences (type, location, level of subbase layer) by means of power regression for each phase of measurements.

When determining regression equation of dependence $E_{\text {ekv }} / M_{z}$ all the results of 108 static loading tests with material according to STN 721512 (gravel $K 1$ ) were taken into consideration. The power equation (3) correlates best for describing the above mentioned dependence: 


\begin{tabular}{|c|c|c|c|c|c|c|c|c|c|c|c|c|c|}
\hline \multirow{3}{*}{ 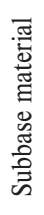 } & \multirow[t]{3}{*}{ Cycle } & \multicolumn{12}{|c|}{ Construction layer } \\
\hline & & \multicolumn{2}{|c|}{$\begin{array}{l}\text { Subgrade surface } \\
\text { before cycle }\end{array}$} & \multicolumn{2}{|c|}{$\begin{array}{l}\text { Subbase layer } \\
150 \mathrm{~mm}\end{array}$} & \multicolumn{2}{|c|}{$\begin{array}{l}\text { Subbase layer } \\
300 \mathrm{~mm}\end{array}$} & \multicolumn{2}{|c|}{$\begin{array}{c}\text { Subbase layer } \\
450 \mathrm{~mm}\end{array}$} & \multicolumn{2}{|c|}{$\begin{array}{c}\text { Subbase layer } \\
600 \mathrm{~mm}\end{array}$} & \multicolumn{2}{|c|}{$\begin{array}{l}\text { Subgrade surf. } \\
\text { after cycle }\end{array}$} \\
\hline & & $\begin{array}{c}E_{0} \\
(\mathrm{MPa})\end{array}$ & $\begin{array}{l}E_{d e f 2} / \\
E_{d e f 1}\end{array}$ & $\begin{array}{c}E_{e k v} \\
(\mathrm{MPa})\end{array}$ & $\begin{array}{l}E_{d e f 2} / \\
E_{d e f 1}\end{array}$ & $\begin{array}{c}E_{e k v} \\
(\mathrm{MPa})\end{array}$ & $\begin{array}{l}E_{d e f 2} / \\
E_{d e f 1}\end{array}$ & $\begin{array}{c}E_{e k v} \\
(\mathrm{MPa})\end{array}$ & $\begin{array}{l}E_{d e f 2} / \\
E_{d e f 1}\end{array}$ & $\begin{array}{c}E_{e k v} \\
(\mathrm{MPa})\end{array}$ & $\begin{array}{l}E_{d e f 2} / \\
E_{d e f 1}\end{array}$ & $\begin{array}{c}E_{0} \\
(\mathrm{MPa})\end{array}$ & $\begin{array}{l}E_{\text {def2 }} / \\
E_{d e f 1}\end{array}$ \\
\hline \multirow{3}{*}{$\begin{array}{l}\stackrel{\sim}{n} \\
\stackrel{2}{2} \\
z \\
\text { Z }\end{array}$} & Separating geotextile & 7.27 & 2.38 & 16.0 & 2.09 & 37.4 & 1.82 & 62.1 & 1.67 & 82.2 & 1.60 & 9.80 & 2.27 \\
\hline & Reinforced geocomposite & 6.85 & 2.40 & 14.0 & 2.14 & 37.0 & 1.82 & 61.8 & 1.67 & 79.8 & 1.60 & 9.40 & 2.28 \\
\hline & $\begin{array}{c}\text { Separating geotextile } \\
\text { non-rigid geogrid }\end{array}$ & 7.22 & 2.38 & 14.2 & 2.13 & 30.4 & 1.88 & 64.6 & 1.66 & 81.9 & 1.58 & 12.5 & 2.18 \\
\hline
\end{tabular}

$$
E_{e k v}=\left(3.3 / M_{z}\right)^{6}
$$

The correlation coefficient $R=0.911$ was determined from the equation (3). It represents a very good correlation dependence. The graphic representation of correlation analysis is in Figure 5.

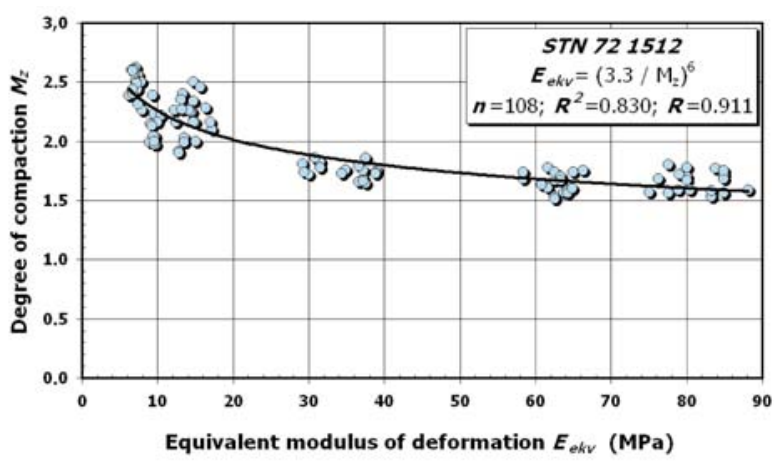

Fig. 5. Regression and Correlation Analysis of Relation $E_{e k v} / M_{z}$

\section{The regression and correlation analysis of dependence $E_{s} / E_{d}$}

An attempt to limit static plate loading tests for diagnostics of deformation resistance of the railway substructure has been observed recently. Less time-consuming tests which take into consideration the dynamic regime of material loading built-in in the railway substructure construction and do not require counter balance are more often applied in practice. The result of the dynamic plate loading test is a dynamic module of elasticity $E_{d}$, which is different from static module of deformation $E_{s}$ because of the principle of diagnostics. The relation between dynamic module of elasticity and static module of deformation depends on the type and deformation resistance of the ground material and can be expressed by comparing measurement. Mathematic relations between $E_{s}$ and $E_{d}$ were derived from of the tests realized on the testing model at DRETM. This time the structure of railway substructure construction was not changed, only granularity of ground material of the subbase varied.
Three cycles of experimental measurements were realized with reinforced geocomposite built in the subgrade surface whose deformation resistance was about $E_{0}=7.0 \mathrm{MPa}$. The subbase consisted of three various types of granulated gravel with fraction of $0 / 32 \mathrm{~mm}$ (fractional crushed gravel $K 1, K 2$ and $K 4$ - Fig. 2) which was in accordance with the required granularity (STN 72 1512). The subbase construction was built in layers of 150, 300, 450 and $600 \mathrm{~mm} .15$ dynamic loading tests were realized before and also after six static loading tests (see the positions $1-15$ and $A 1-C 2$ in Fig. 1). 360 dynamic and 72 static loading tests were analyzed in three cycles of experimental measurements.

The overview of regression and correlation analysis of static and dynamic loading tests (on the subbase surface) for individual tested constructions with various subbase materials can be seen in Figs. 6, 7 and 8. Fig. 9 shows all the results of experimental measurements regardless to the type of ground material.

\section{Conclusion}

Better compaction of the substructure causes reduction of the pores volume in the ground that means reduction of its permeability, especially if the subgrade surface consists of ground which is sensitive to water influence. That mean the compaction has a great importance in prevention of the reduction of the deformation. The reduction of the pores volume in the subbase causes the increase of shear resistance and so the deformation resistance of the railway substructure is increasing. All these reasons are important not only for reduction of water influence on the subgrade surface but also for increasing quality of the whole railway track construction because both the railway substructure and the railway superstructure (subgrade and track panel) form a technical and physical unit, in which each construction part has its share on the railway traffic loading. Good compaction of the railway substructure materials can reduce and also eliminate permanent deformations of the railway track and also reduce maintenance costs. With the reduction of the subbase construction thickness a more economical design of the railway track construction will be reached.

The experimental measurements proved that not only the type of tested ground (granularity curve) but also compaction measurements have a remarkable influence on the correlation. The more 


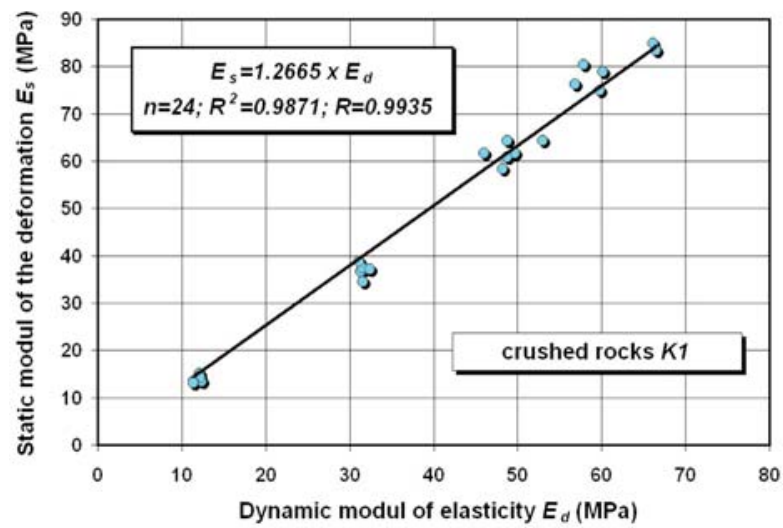

Fig. 6. Correlation estimation of $E_{s} / E_{d}$ for granulated gravel $K 1$

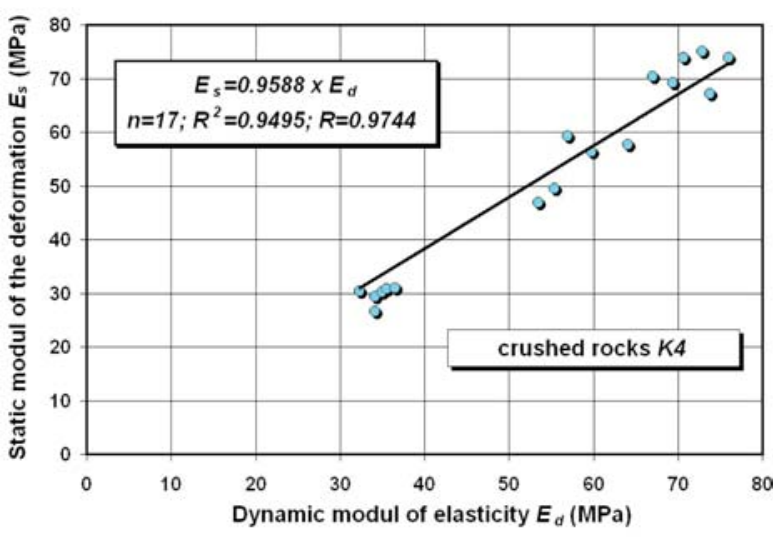

Fig. 8. Correlation estimation of $E_{s} / E_{d}$ granulated gravel $K 4$

coarse-grained material of the subbase was, the higher correlation coefficient was reached. The experiments also proved the fact that dynamic loading tests are less suitable for materials with higher proportion of fine fraction.

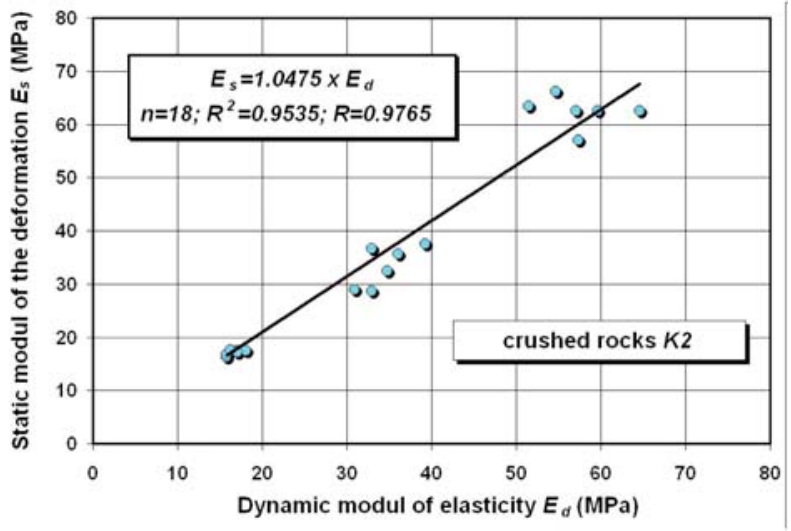

Fig. 7. Correlation estimation of $E_{s} / E_{d}$ for granulated gravel $K 2$

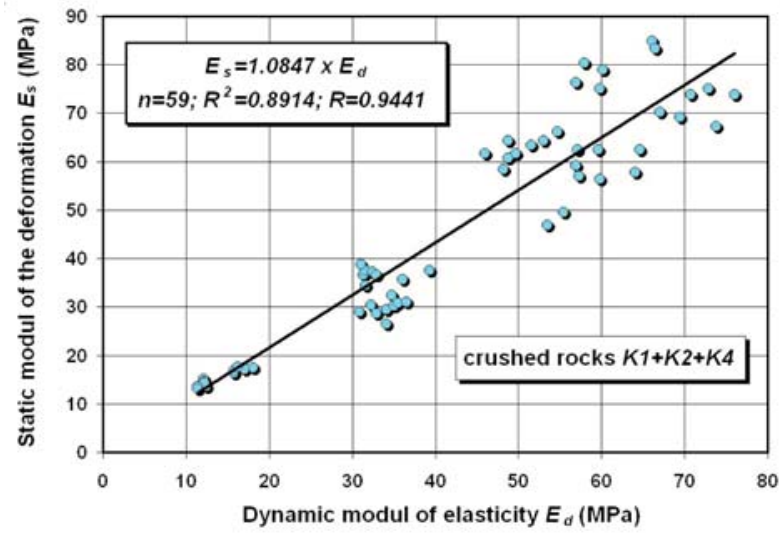

Fig. 9. Correlation estimation of $E_{s} / E_{d}$ granulated gravel $K 1+K 2+K 4$

The authors of the paper would like to thank the grant commission VEGA for supporting the project No. 1/0341/03, which allows the realization of experimental measurements and consequently obtaining relevant results that are presented in this paper.

\section{References}

[1] Instruction S4 of the Slovak Railways „Railway substructure”, NADAS Praha, operation of $1^{\text {th }}$ January 1988 